\title{
Knowledge, Attitudes and Practices Regarding Blood Donation Among People From Various Areas in Karachi
}

\author{
Kiran Ata-ur-Rehman, Ramsha Nighat*, Khalida Shakoor, Samar Tauseef, Umama Rashid, and \\ Talia Hasam
}

Hamdard Collage of Medicine and Dentistry, Karachi, Pakistan.

\begin{abstract}
Background: Over 90\% of total blood transfused in Pakistan is donated by the friends and relatives of patients. The population of Karachi particularly healthy and active individuals can be a good source of quality blood if they are motivated and are willing to be voluntary blood donors. Therefore the objective of this study is to determine the knowledge, attitudes and practices about blood donations among people of Karachi.
\end{abstract}

Methods: A cross sectional study was conducted among people of Karachi from April 2015 to September 2015 . A total of 300 people were interviewed with the help of structured questionnaire. Data analysis was performed in SPSS version 20.

Results: The study showed that the frequency of blood donation was significantly higher in males than females. In total, 273 of the participants have knowledge about blood donation whereas the remaining 27 participants were unaware. In total, 230 participants never donated blood. Regarding attitudes of participants, study showed that 31\% participants think that they are weak, $23.7 \%$ told that it's harmful, $23 \%$ told that they are diseased, and $23.3 \%$ told that they have a fear of getting sick/infected.

Conclusion: Attitudes and performance regarding blood donation was less than satisfactory among the participants as compared to knowledge and awareness, this may be due to misconceptions, misbelieves and restrictions. An intensive campaign should be implemented to encourage public about blood donation to alleviate their fears and to change their perceptions.

Keywords: Blood Donation, People living in Karachi, Knowledge, Attitude, Practices.

doi.org/10.21089/njhs.21.0020

\section{INTRODUCTION}

"More blood, more life" [1] this was the theme for World Blood Donor Day towards emphasizing the critical need for more people all over the world to become life savers by donating blood regularly. World Blood Donor Day is celebrated on the 14th of June every year to mark the birth anniversary of Karl Landsteiner who discovered the blood group system [2]".

Around 93 million blood donations are donated annually by all types of blood donors (based on reports from 173 countries) [3].

Blood donation refers to the process of collecting, testing, preparing and storing blood and blood components [4]. According to World Health Organization (WHO), the estimated blood requirement for Southeast Asian region is approximately 16 million units per annum, but is able to col-

*Address correspondence to this author at the Hamdard Collage of Medicine and Dentistry, Karachi, Pakistan.

E-mail: rami1940@outlook.com lect just 9.4 million units, leaving a gap of six million units [3]. The individuals which give blood voluntarily are called Blood Donors. According to WHO there are three types of blood donors [3]:

1. Voluntary unpaid

2. Family/replacement

3. Paid

Most donations are as a result of replacement donations, which are non- remunerated donations, provided by the relatives of patients. Paid donors are those who donate blood in exchange for money. Replacement and paid donors may be compelled to donate blood, though their health conditions are unsuitable to donate blood. They do not help maintaining a stock of blood for emergency situations.

Of the 108 million blood donations collected globally, approximately half of these are collected in the high-income countries, home to $18 \%$ of the world's population. This however has shown an increase of almost $25 \%$ from 80 million donations collected in 2004 [3]. 
In Pakistan more than 1.5 million pints of blood are collected each year. Among them about $65 \%$ is from replacement donors, $25 \%$ from volunteer donors and about $10 \%$ from professional donors. The concept of voluntarily nonremunerated donors is mainly absent due to the lack of a blood donor recruitment and retention strategy.

The most prominent reason why people give blood is altruism beside community needs and support, family assurance and social pressure. On the other hand fear, lack of knowledge has proved to be primary obstacles for blood donation [5].

According to an estimate, over $70 \%$ blood donations in Pakistan are replacement or paid for donations [6].

Pakistan, with its limited resources, has 170 public and 450 private blood banks that are mostly hospital based. The system, however, lacks information regarding retention of donors, record keeping and recruitment of donors in most of the blood banks. A study done in Pakistan revealed inadequate knowledge, inappropriate attitude and misconceptions about blood donation among Army personnel as well [7].

\section{OBJECTIVES}

1. To determine the awareness among people regarding blood donation

2. To determine the knowledge among people towards blood donation

3. To assess the attitudes and behavior of people before and after donating blood

4. To understand the physical and psychological reaction after blood donation.

\section{MATERIALS AND METHODS}

This questionnaire based cross sectional descriptive study was conducted during April 2015 - September 2015 in different areas of Karachi. Cluster sampling technique has been used in this research, the target was mainly the common people aged between 18-45 years. A total of 300 people were included in the study. The participants were briefed about the objective of this study and verbal consent was taken. Pretest was also conducted which included 30 participants. The statistical analyses were done by using SPSS software.

\section{RESULTS}

The mean age of the population was between 20-30 years. The questionnaire was completed by 300 participants, of whom $235(78.3 \%)$ were male and $65(21.7 \%)$ were female (Table 1), it showed that frequency of blood donation was significantly higher in males as compared to females. Among our study population 138 (46\%) were unemployed, $32 \%$ were student, $8 \%$ were self- employed, $8.7 \%$ were gov- ernment employed, whereas $5.3 \%$ were private sector employed (Table 2). Overall it was noticed that the unemployed persons contributed to a greater part among our study population. In total, $273(91 \%)$ of the population had knowledge about blood donation, whereas 27 (9\%) of the population were unaware. So, it shows that the people of Karachi have good knowledge about blood donation. 223 (74.3\%) of our study population donated blood in order to save someone's life, whereas aim of other participants were sympathy $7 \%$, charity $8 \%$, money $14.7 \%$, on the other hand $2.3 \%$ participants had no aim and inspiration regarding blood donation (Table 3). Among the participants, about $10 \%$ had donated blood just once, $10.7 \%$ for 3-5 times, $2 \%$ for 5-10 times and $7 \%$ for $>10$ times but the evaluating thing in our study was that $230(76.7 \%)$ of the people never donated blood (nondonors). . In order to find out the level of knowledge about the frequency of blood donation we came to know that 115 (38.3\%) persons knew that there should be a 6 months gap, however $13.7 \%$ population told that it should be a 2 months gap, $31 \%$ population for 3 months gap and $17 \%$ population for 4 months gap (Table 4).

About 199 (66.3\%) think that they could donate blood, whereas $101(33.7 \%)$ did not want to donate blood, $31 \%$ think they are weak , 23.7\% think that it is harmful, $23 \%$ were diseased and $23.3 \%$ have fear of getting sick/infected. About 133 (44.3\%) people stated that blood donation can get them infected due to unsterilized needle. Similarly, $16.3 \%$ population think that the site of needle's insertion may be painful, $38.3 \%$ people have a fear that they may faint, $7 \%$ of the population have a misconception of infertility and $3 \%$ of the people think that if they donate blood then the blood recipient will become their half-brother/sister.

\section{DISCUSSION}

Blood donation is very important issue which has to be focused. According to our study, $76.6 \%$ of the populations in Karachi are non-donors, $13.4 \%$ are regular donors and $40 \%$ are voluntary donors. The donors who regularly donate are mostly between the age of 20-30 years, among these the incidence of male donation is far more better in Karachi than other countries, but despite those females who have a spirit to donate blood are not independent to give blood with freedom due to cultural and family matters. Family plays an important role in guidance and knowledge of the people.

\section{What was the Reason Behind?}

The majority said that to save someone's life is just like saving the whole humanity but unfortunately $76 \%$ people still never donate blood. Besides having this beautiful spirit $49 \%$ people donate blood only in emergency to their family members but not to other people because of cultural misconceptions and misbelieve. 
Table 1. Frequency distribution of the participant's sex.

\begin{tabular}{|c|l|c|c|c|c|}
\hline \multicolumn{2}{|c|}{} & Frequency & Percent & Valid Percent & Cumulative Percent \\
\hline \multirow{5}{*}{ Valid } & Male & 235 & 78.3 & 78.3 & 78.3 \\
\cline { 2 - 6 } & female & 65 & 21.7 & 21.7 & 100.0 \\
\cline { 2 - 6 } & Total & 300 & 100.0 & 100.0 \\
\hline
\end{tabular}

Table 2. Frequency distribution of participant's occupation.

\begin{tabular}{|c|c|c|c|c|c|}
\hline & & Frequency & Percent & Valid Percent & Cumulative Percent \\
\hline \multirow{4}{*}{ Valid } & Unemployed & 138 & 46.0 & 46.0 & 46.0 \\
\hline & Self employed & 24 & 8.0 & 8.0 & 86.0 \\
\hline & Private sector employed & 16 & 5.3 & 5.3 & 100.0 \\
\hline & Total & 300 & 100.0 & 100.0 & \\
\hline
\end{tabular}

Table 3. Frequency distribution of aim of blood donation.

\begin{tabular}{|c|c|c|c|c|c|}
\hline & & Frequency & Percent & Valid Percent & Cumulative Percent \\
\hline \multirow{4}{*}{ Valid } & to Save Someone's Life & 223 & 74.3 & 74.3 & 74.3 \\
\hline & Charity & 24 & 8.0 & 8.0 & 97.0 \\
\hline & none of them & 7 & 2.3 & 2.3 & 100.0 \\
\hline & Total & 300 & 100.0 & 100.0 & \\
\hline
\end{tabular}

Table 4. Frequency distribution of the participants.

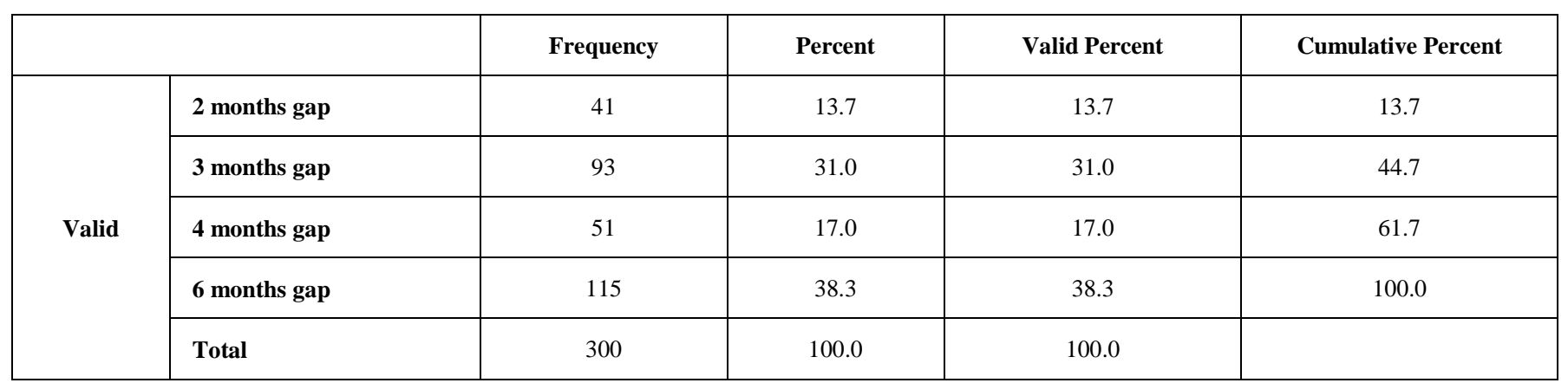

As $91 \%$ have knowledge about blood donation, they have also positive attitudes but they resist to donate blood because of lack of time, fear of complications and anemic, which act as a barrier in both sexes. 
Our study reveals that more than that $66.3 \%$ of people want to donate blood because they had a positive and healthy attitude towards blood donation yet $33.7 \%$ of our respondents are not willing to donate blood due to weakness/disease or just because they are afraid of the process. $33.3 \%$ of our donors agreed that they have been donating blood so as they will get a complementary blood screening for major diseases like hepatitis, HIV etc.

Non donors expressed their fear of needle, getting faint or in some cases becoming infertile. People from specific areas have shown the fear of alterations in their relationship with family members. Although we unfortunately found out that professional blood donor tend to donate blood without consideration of time period just to get money/cash for their major requirements/addictions.

\section{CONCLUSION}

An intensive campaign should be implemented to encourage public about blood donation to alleviate their fears and to change their perceptions. Barriers to blood donation have to be properly investigated and evaluated. Qualitative surveys should be done in order to rule out individual's decision to give blood. An adequate reward that suits the community could be developed for these donors and also encouraging especially to those people who have knowledge but still refuse to donate blood because of lack of time.

\section{ACKNOWLEDGEMENT}

Declared None.

\section{CONFLICT OF INTEREST}

Declared None.

\section{REFERENCES}

[1] A. Farruugia. More blood, more life? Reflections on World Blood Donor Day - 2011. Indian J. Medl Res., 2011; 133(6): 573-576.

[2] A. Tharu. Blood Donation. Available from: http://www.medindia.net/patients/patientinfo/blooddonation.htm

[3] Blood safety and availability. Available from: http://www.who.int/mediacentre/factsheets/fs279/en/

[4] N. Ahmed, S. Kumar R. A guide to organizing a voluntary blood donation camp. Inter. J. Blood Trans. Immunohematol., 2013; 3:1318.

[5] N. Alfouzan. Knowledge, attitudes, and motivations towards blood donation among king abdulaziz medical city population. Inter. J. Family Med., 2014;

https://www.hindawi.com/journals/ijfm/2014/539670/ID539670

[6] S. Saleem, A. Wasim, S. Sabih, A.F. Khan, M.H. Rizvi, U.A. Jillani, et al. Assessing acceptability of short message service based interventions towards Becoming Future voluntary blood donors. $J$. Blood Trans., 2014; ID567697

[7] F.H. Mohammad, T. Ashfaq, K. Nanji, Q. Anjum, M.I. Lohar. Knowledge and attitudes towards voluntary blood donation among Students of a Private Medical College. Infectious Diseases J. Pakistan., 2011; 20(1): 273-276. 